\title{
LAS MOTIVACIONES DEL VOTO EN EL CONCURSO DE ACREEDORES \\ (IN RE DBSD NORTH AMERICA, INC. 634 F.3D 79 (2011))
}

\section{THE MOTIVES OF THE VOTE IN A BANKRUPTCY PROCEEDING (IN RE DBSD NORTH AMERICA, INC. 634 F.3D 79 (2011))}

\section{JUAN LUis Goldenberg SERRANO*}

\section{1) INTRODUCCIÓN}

En el caso de In re DBSD North America, Inc. ${ }^{1}$, los tribunales norteamericanos tuvieron nuevamente la posibilidad de evaluar los supuestos en los que procede descartar aquellos votos sufragados de mala fe en un proceso concursal. El fallo ha sido recibido con un cierto nivel de alarma por el foro especializado ${ }^{2}$ puesto que, como ya anticipaba Africk, una lectura fácil de la norma puede poner en peligro las bases de un "mercado de deuda basura" (o, más políticamente correcto, "distressed debt market"), en el que los adquirentes (normalmente, inversionistas institucionales de alta sofisticación) pretenden obtener ganancias mediante una decisiva participación en la decisión de los destinos de la empresa ${ }^{3}$. En ellos, la intención

Doctor en Derecho, Universidad de Salamanca. Profesor de Derecho Civil de la Facultad de Derecho de la Pontificia Universidad Católica de Chile. Dirección Postal: Av. Libertador Bernardo O’Higgins N³40, Santiago. Correo electrónico: jgoldenb@uc.cl. Este trabajo se inscribe en el proyecto Fondecyt de Iniciación de Investigación Nº 11121139 (“Fundamentos Dogmáticos de la Visión Privatista del Derecho Concursal').

1 In re DBSD North America, Inc. 634 F.3d 79 (2011). Disponible en: https://coursewebs.law. columbia.edu/coursewebs/cw 12S L8247 001.nsf/0f66a77852c3921f852571c100169cb9/ FD335A07DC964EBF85257989000063C5/\$FILE/SC+-+Dish Network Corp v DBSD Nort-[1].pdf?OpenElement [fecha de visita 7 de enero de 2013].

2 Goffman, Jay M. y LovetT, Suzanne D.Y. (2010). "Confirmation Hot Topics". Bankruptcy 2010: Views from the Bench. New York: American Bankruptcy Institute, pp. 150 - 152.

3 Africk, Andrew (1991). "Trading claims in Chapter 11: How much influence can be purchased in good faith under section 1126". University of Pennsylvania Law Review, Vol. 139, N ${ }^{\circ}$ 5, pp. 1.393-1.422, pp. 1.416-1.419. 
del voto no estará puramente dada por el objetivo de protección del crédito, sino más bien por las motivaciones propias de un inversionista que pretende redituar con mayor éxito el crédito en desgracia ${ }^{4}$.

Sin embargo, nos interesa explorar este fallo, como asimismo la norma jurídica que lo sustenta, por cuanto entendemos que la posibilidad de revisar la motivación del voto por parte de la legislación norteamericana no es sino una de las tantas reglas que pretenden conceder unidad a una mirada típicamente privatista del Derecho concursal. Como expresaremos a continuación, si de algún modo el voto debe ser emitido en función de la posibilidad de maximizar las posibilidades de cobro de los acreedores, ello no es sino resultado de comprender que, en esta formulación del concurso, el interés supremo es la tutela del crédito. Las demás finalidades (propiamente, sancionatorias al deudor o conservativas de la empresa) estarán de algún modo subordinadas a tal pretensión principal, de manera que es fácil seguir la huella hasta entender que, tratándose de un interés más bien particular, el mecanismo específico de solución de la crisis debe ser entregado a los propios interesados (en este caso, los acreedores). Cualquier distorsión en tal esquema debe ser rechazado, como el que supone un comportamiento estratégico por parte de los acreedores que, haciendo uso del derecho a voto, no se cohonesten con tal fin de eficiencia. En caso contrario, peligra la justificación del modelo concursal legalmente adoptado.

Pero traemos a colación el tema porque el ordenamiento jurídico chileno se ha orientado de manera similar, al menos en relación a este enfoque privatista de sus normas, especialmente a partir de la Ley $\mathrm{N}^{\circ}$ 18.175 , de 28 de octubre de 1982 (incrementado por las reformas posteriores, especialmente por la Ley $\mathrm{N}^{\circ} 20.073$, de 29 de noviembre de 2005), y así se pretende acentuar aún más en el proyecto de reforma de la legislación concursal, el cual ha tenido particularmente en cuenta la eficiencia del sistema 5 . Y nos interesa revisar la reacción normativa dispuesta en el ordenamiento comparado, especialmente, en atención a que nuestro sistema actualmente no cuenta con esta clase de normas de cierre, como

4 Roulllon, Adolfo (2007). "El cambio del paisaje concursal a comienzos del siglo XXI". Anuario de Derecho Concursal, $\mathrm{N}^{\circ} 11$, pp. 253-261, hace referencia a este fenómeno bajo la idea del "cambio de acreedores". Así, expresa que "Las hasta hace muy poco despreciables deudas morosas de un deudor confesadamente insolvente, hoy han encontrado adquirentes en los mercados de deuda de esa clase. No se trata de solitarios aventureros, dispuestos a apostar ocasionalmente a la adquisición de deuda-chatarra, sino de entidades financieras o de inversión, algunas de ellas de renombre y con largo arraigo, o de fondos especializados en la compra de créditos concursales, a valores descontados. Este es también un fenómeno que marca una tendencia mundial, aunque en el país y en la región sea más reciente que en el hemisferio norte”.

5 La valoración de la eficiencia del sistema concursal chileno es uno de los motores del Proyecto de Ley de Reorganización y Liquidación de Empresas y Personas, conforme consta del Mensaje 081-360, de 15 de mayo de 2012 (Sección II). 
sí lo hace de algún modo el derecho concursal proyectado. Así, el inciso segundo el artículo 191 del proyecto de reforma concursal, propone, aunque únicamente en sede de liquidación, que "Los acreedores que tengan un interés particular distinto del inherente a la calidad de acreedor del deudor, en un determinado acuerdo deberán abstenerse de votar dicho acuerdo y tampoco se considerarán en el cálculo de dichos quórums".

\section{2) EXPlicación de los HeChOS EN IN RE DBSD NORTH AMERICA, INC.}

El caso en estudio puede resumirse del siguiente modo: con fecha 15 de mayo de 2009, DBSD North America, Incorporated y algunas de sus filiales (en adelante, "DBSD"), todas relacionadas al giro de la creación de redes de comunicaciones móviles, presentaron una solicitud voluntaria de bancarrota ("bankruptcy") ante el Tribunal de Bancarrotas del Distrito Sur de Nueva York, dando cuenta de deudas por un monto de aproximadamente 813 millones de dólares, sobre un activo valorado en 627 millones de dólares. La conformación de su pasivo daba cuenta de tres niveles de deuda claramente diferenciados: (i) un primer nivel de deuda garantizada ("first lien debt") del orden de 40 millones de dólares, proveniente de ciertas aperturas de créditos rotativas contratadas en el año 2008; (ii) un segundo nivel de deuda garantizada ("second lien debt"), de aproximadamente 650 millones de dólares, correspondiente a bonos garantizados emitidos por el deudor en agosto de 2005; y (iii) un último nivel de deuda, correspondiente al crédito de Sprint Nextel Corporation, ilíquido y valista ("unsecured"), basado en una demanda presentada por este en contra de una de las filiales de DBSD, por un monto total de 211 millones de dólares (aunque el tribunal solo aceptó provisionalmente un monto de 2 millones de dólares para efectos de la votación).

Ante tal escenario, DBSD propuso un plan de reorganización al amparo del Capítulo 11 de la legislación concursal norteamericana (United States Code 11, o, simplemente, "USC 11"), basado en dos ejes principales: por una parte, centrarse únicamente en la continuación de su negocio nuclear ("core business"), y, por la otra, reestructurar su pasivo mediante: (i) la novación de los créditos de primer nivel por nuevos créditos, con vencimiento dentro de cuatro años, manteniendo la tasa de interés vigente (12,5\%), pero pagando los mismos en especie ("payment in kind"); (ii) la capitalización de los créditos del segundo nivel de deuda garantizada, ofreciendo acciones en la entidad reorganizada representativas de al menos el $51 \%$ de los montos originalmente adeudados (conforme a la estimación del propio tribunal); y (iii) la capitalización del crédito valista, ofreciendo acciones en la entidad reorganizada representativos de al me- 
nos el $4 \%$ de los montos originalmente adeudados (también, conforme a la estimación del tribunal).

Sin perjuicio de las objeciones de Sprint Nextel Corporation (el único acreedor valista), quien entendía que el plan vulneraba la regla de prioridad absoluta ("absolute priority rule" contemplada en la sección 1129(b)(2)(B)(ii) USC 11) ${ }^{6}$, este comentario se centra en las objeciones efectuadas por el propio deudor en razón del voto efectuado por uno de sus acreedores. La historia relatada en la propia resolución da cuenta que DISH Network Corporation (en adelante, "DISH”) adquirió la totalidad de los créditos de primer nivel a su valor nominal, como también parte de los créditos correspondientes al segundo nivel de deuda, a efectos de asegurar una posición de bloqueo del plan propuesto por DBSD. Especial atención debe prestarse al hecho de que DISH era un competidor directo del deudor (en lo que se refiere a la utilización y manejo de satélites), al tiempo que poseía una participación relevante en TerreStar Corporation, un competidor directo del deudor en el desarrollo de las redes de comunicaciones móviles.

En la deliberación del plan propuesto por DBSD, como era de esperar, DISH votó por su rechazo, argumentando su falta de viabilidad ("feasibility test" contemplado en la sección 1129(a)(11) USC 11) y al hecho que el ofrecimiento al acreedor de primer nivel no cumplía con el requisito de equivalencia indubitable ("indubitable equivalent") exigido para forzar la aprobación (mediante el sistema de "cramdown") respecto a los acreedores que hubiesen disentido del acuerdo, en los términos de la sección 1.129(b)(2)(a)(iii) USC 117 . El deudor, sin embargo, alegó la ausencia de buena fe en el voto de DBSD, solicitando al tribunal que, conforme a las atribuciones conferidas en la sección 1.126(e) USC 11, procediera a descartar ("designate") el voto de DISH, y, en consecuencia, el plan se estimase finalmente aprobado por la votación favorable del resto de los acreedores.

El tribunal estimó que efectivamente estaba autorizado para la privación del voto (no así el rechazo del acuerdo), fundamentado en que DISH no había emitido el mismo de buena fe, sino como parte de una estrategia enfocada a ejercer control sobre los activos más relevantes del deudor (especialmente, sus satélites). Y, como consecuencia de lo anterior,

6 Esta regla, nos informa Warren, Elizabeth (2008) Chapter 11: Reorganizing American Business. Nueva York: Wolters Kluwer, Aspen Publishers, pp. 155 - 157, ha sido creada para proteger a los acreedores en un sistema de confirmación forzada ("cramdown"), conforme a la cual el plan de reorganización no puede conceder beneficios a las clases inferiores (incluyendo no solo a los acreedores inferiores, sino también a los accionistas del deudor) a menos que las clases superiores hubiesen aceptado el plan (sin confirmación forzada) o hubiesen sido íntegramente pagadas. Para una explicación de la historia legislativa, motivaciones y contenido de esta forma de aprobación, Broude, Richard (1984). "Cramdown and Chapter 11 of the Bankruptcy Code: the settlement imperative". The Business Lawyer, $N^{\circ} 39$, pp. $441-454$. 
tuvo por aprobado el acuerdo de reorganización presentado por el deudor, tomando únicamente en consideración el voto positivo de los demás acreedores. DISH apeló a dicho fallo ante la Corte de Apelaciones del Segundo Distrito de los Estados Unidos, cuya resolución, confirmatoria de la anterior, pasamos a explicar y comentar.

\section{1) CONSIDERACIONES LEGALES Y JURISPRUDENCIALES}

\section{Origen de la sección 1.126(e) USC 11}

En su parte relevante, la sección 1.126(e) USC 11 dispone lo siguiente: "A petición de una parte interesada, y luego de la notificación [de la solicitud] y la audiencia, el tribunal puede descartar cualquier entidad cuya aceptación o rechazo de tal plan no fue de buena fe..." ${ }^{8}$. El texto antes transcrito es original del Código de Bancarrota norteamericano de 1978, pero sus antecedentes se encuentran en la Chandler Act de 1938, producto de una modificación a la legislación entonces vigente, basada en el impacto generado por la resolución del caso Texas Hotel Securities Corp. v. Waco Development Co. (87 F.2d 395 (5th Cir. 1936)'.

En el referido caso, el tribunal no había encontrado justificaciones legales para desechar el voto de uno de los acreedores (Conrad Hilton), quien expresó que había adquirido créditos solo para bloquear el plan de reorganización presentado por el deudor, de modo tal que pudiese volver a administrar el hotel Roosevelt (principal activo del deudor) o, al menos, restablecer los derechos que estimaba tener sobre dicho inmueble. El tribunal estimó que, a la fecha, no se permitía a los tribunales indagar ni valorar las motivaciones de los acreedores al momento de emitir el voto, y, menos aún, ofrecer herramientas que impidiesen o anulasen el mismo.

La decisión del tribunal fue motivo de especial preocupación por parte de la Security and Exchange Commission, al punto que esta promovió una reforma de la Bankruptcy Act ante el Congreso norteamericano ${ }^{10}$. El comisionado de dicha agencia estatal, William O. Douglas, compareció ante el comité parlamentario a modo de explicar la necesidad de insistir

8 Traducción del autor. En su lengua original, esta sección dispone que "On request of a party in interest, and after notice and a hearing, the court may designate any entity whose acceptance or rejection of such plan was not in good faith ... ".

9 Disponible en: http://www.leagle.com/xmlResult.aspx?xmldoc=193648287F2d395 1354. xml\&docbase=CSLWAR1-1950-1985 [fecha de visita 7 de enero de 2012].

10 Resultado de lo anterior fue la incorporación de la sección 203 al Bankruptcy Act, predecesora de la regla actual, que disponía que "Si la aceptación o la falta de aceptación de un plan por el tenedor de un crédito o de una acción no es de buena fe, a la luz de o sin perjuicio de la época de su adquisición, el juez puede, luego de la audiencia notificada, disponer que tal crédito o acción sea descalificado a efectos de determinar el requisito de mayoría para la aceptación de un plan" (traducción del autor) . 
en la incorporación de un estándar de "buena fe" en las votaciones por parte de los acreedores, expresándose en términos que quedaron en la mente de los tribunales al tiempo de resolver los casos presentados con posterioridad a la modificación legal: no deberían existir "razones ulteriores ("ulterior reasons") para sus acciones"11. Así, la interpretación jurisprudencial de la sección 1.126(e) USC 11 resulta desde una mirada histórica, especialmente en comparación con el caso Waco, como si no quisiesen repetirse las consecuencias de una conducta reprochable, pero incorrectamente abordada por la legislación entonces en vigor ${ }^{12}$.

\section{2) SOBRE EL CONCEPTO DE BUENA Y MALA FE PARA EFECTOS DE LA PRIVACIÓN DEL DERECHO A VOTO}

Como la literatura norteamericana apunta, la regulación concursal no contiene definiciones ni establece criterios específicos para determinar el comportamiento de buena o mala fe por parte de los acreedores al tiempo de emitir su voto ${ }^{13}$. Ello, casi de manera consciente por parte del legislador, a efectos de dar mayor flexibilidad a los tribunales en la valoración de la conducta específica del votante, basado en las particularidades de cada caso ${ }^{14}$. En In re Figter Ltd., el tribunal describió este punto del siguiente modo: "El concepto de buena fe es fluido, y no existen factores únicos que inexorablemente impliquen un resultado final, como tampoco un determinado conjunto de factores puede ser considerado [a estos efectos]. Siempre es necesario tener presente la diferencia entre el interés propio del acreedor como acreedor y el motivo que es ulterior al propósito de proteger los intereses del acreedor" 15 .

Sin perjuicio de lo anterior, y a modo de dar mayor objetividad a la norma, la jurisprudencia se ha hecho constantemente eco de las palabras del comisionado Douglas, comprendiendo que la mala fe se expresa en aquellos casos en los que el acreedor ha actuado con motivaciones ulteriores ("ulterior motives") 16 . La aclaración no parece ser suficiente, dado que no especifica cuáles son las razones que pueden justificar la forma en la que un determinado acreedor ejerce su derecho a voto, razón por la cual

In re DBSD North America, Inc. (Sección II.A.1).

In re DBSD North America, Inc. (Sección II.A.1).

Por todos, Kidder, Samuel M. (2010-2011). "What's your position? Amending the Bankruptcy disclosure rules to keep pace with financial innovation". UCLA Law Review, N 803, pp. 803 - 841, p. 840 .

14 In re DBSD North America, Inc. (Sección II.A.1).

15 In re Figter Ltd., 118 F.3d 635, 638 (9th Cir. 1997) (Discussion, Sección A) (traducción del autor. Disponible en: http://www.leagle.com/xmlResult.aspx?page=3\&xmldoc=1997753118F3 d635 1666.xml\&docbase=CSLWAR2-1986-2006\&SizeDisp $=7$ [fecha de visita 7 de enero de 2013].

16 In re DBSD North America, Inc. (Sección II.A.1). 
los propios tribunales han debido efectuar ciertas precisiones para delinear el concepto.

En primer lugar, cabe considerar que la doctrina ha expresado que ha de comprenderse que el voto es la principal medida de protección de los acreedores en el contexto concursal ${ }^{17}$. En un sistema en el que la resolución del dilema que supone la insolvencia del deudor es puesto en cabeza de los acreedores (la regla general, nos indican las secciones 1.126 y 1.129 (a)(8) USC 11, es que todos los acreedores deban concurrir con su voto a la confirmación del plan de reorganización), el voto resultará en la herramienta fundamental con la que estos cuentan para expresar la intención que, a su juicio particular, es la que de mejor manera salvaguarda sus intereses individuales. En este sentido, la privación del derecho a voto debe ser correctamente fundamentada, en tanto debe comprenderse que la sección $1.126(\mathrm{e})$ USC 11 consagra una regla absolutamente excepcional ${ }^{18}$.

En este sentido, la buena o mala fe no se refleja en el egoísmo de los acreedores ("selfishness") ${ }^{19}$, quienes están naturalmente llamados a la conservación de lo propio, y a ignorar, en principio, los efectos de su actuar para el resto de los acreedores, el deudor o cualquier tercero que pueda resultar afectado. Esta evidencia, que descarta cualquier indicio de affectio concusal, impide una valoración (positiva o negativa) del voto por el solo interés protector. De este modo, por ejemplo, en In re Gilbert se estimó que el voto no podía ser descartado por las maniobras emprendidas por uno de los acreedores, que, a fin de asegurar su posición respecto a ciertos créditos preferentes, adquirió otros tantos créditos inferiores a precio de descuento. En este caso, concluyó el tribunal, no habrían existido "motivos ulteriores", en tanto la adquisición (y posterior votación) del referido acreedor no fueron sino reflejo de la propia finalidad protectiva del crédito, sin representar intereses que no sean propios del de los acreedores.

Luego, si el voto resulta en una medida de protección, esta se encuentra justificada en tanto el resguardo se concede a los acreedores en función a sus intereses como tales, y no en atención a otras características o circunstancias propias del sujeto (por ejemplo, su calidad de competidor del deudor, o su intención de abarcar un mayor poder de mercado). En otras palabras, se busca que el acreedor ejercite su derecho a voto únicamente a fin de proteger el crédito, y no en razón de intereses diferentes, y solo en este último caso se hacen sinónimos los criterios de "mala fe" y "motivos ulteriores". En este sentido, resulta crucial el parámetro proporcionado por In re P-R Holdings Corp., en el que el tribunal entendió

\footnotetext{
17 WARREN (2008) 151.

18 In re Adelphia Communications Corp., 359 B.R. 54, 61 (Bankr.S.D.N.Y. 2006) (Sección III). Disponible en: http://www.leagle.com/xmlResult.aspx?xmldoc=2006413359BR54 1407.xml [fecha de visita 7 de enero de 2013].

19 In re DBSD North America, Inc. (Sección II.A.1).
} 
que "El mero hecho de que la adquisición de los derechos de un acreedor se haya hecho con el propósito de asegurar la aprobación o el rechazo de un plano no significa en sí mismo "mala fe". Cuando la adquisición es en ayuda de un interés diferente a su interés como acreedor, tal adquisición puede implicar "mala fe"” 20.

En consecuencia, el ejercicio del derecho a voto no debe ser concebido como una prerrogativa absoluta, sin limitaciones, sino una concesión otorgada por el ordenamiento jurídico en atención a la finalidad propuesta por el sistema concursal ${ }^{21}$. Si bien nos referiremos a este punto con mayor profundidad en la sección siguiente, ello implica que la norma contenida en la sección 1.126(e) USC 11 debe ser comprendida como una regla que confiere consistencia a una visión privatista del concurso, y que justifica las razones por las cuales el ordenamiento llama a los acreedores a decidir sobre la forma de resolución de los problemas que genera la insolvencia del deudor común. Al respecto, llama la atención que la propia sentencia de In re DBSD North America, Inc. aluda a la actuación de buena fe por parte del acreedor como aquella llamada a la maximización del retorno ${ }^{22}$, cuestión que ya se había anticipado en el caso de Allegheny International, Inc. reconduciendo el asunto a la constatación de los intereses económicos del acreedor detrás del voto ${ }^{23}$. En este sentido, la apreciación jurisprudencial de la norma termina por exigir del acreedor un voto económicamente racional, que indudablemente pretenda tal maximización, dirigiéndose a la búsqueda de eficiencia del sistema concursal.

20 In re P-R Holding Corp., 147 F.2d 895, 897 (2d Cir. 1945). Disponible en: http://www. leagle.com/xmlResult.aspx?xmldoc $=19451042147 \mathrm{~F} 2 \mathrm{~d} 895$ 1802.xml\&docbase $=\mathrm{CSL}-$ WAR1-1950-1985 [fecha de visita 7 de enero de 2013] (traducción del autor).

21 De hecho, en Young v. Higbee Co., 324 U.S. 204 (1945), la Corte Suprema norteamericana interpretó la Sección 203 de la Bankruptcy Act (entonces vigente) desde la idea que "históricamente, uno de los principales propósitos de la legislación de bancarrotas ha sido conceder una distribución a pro rata entre los acreedores respecto a los bienes del fallido; proteger a los acreedores unos de otros" (traducción del autor). Disponible: http://caselaw.lp.findlaw.com/scripts/ getcase.pl?navby=search\&court=US\&case=/us/324/204.html [fecha de visita 7 de enero de 2013].

22 El tribunal estimó que la parte adquirente estaba menos interesada en la maximización del retorno de su crédito que en desviar el proceso del procedimiento para alcanzar un beneficio externo ("outside benefit") (In re DBSD North America, Inc. (Sección II.A.1)).

23 En In re Allegheny International, Inc.; 118 B.R. (Bankr. W.D. Pa. 1990), se había sostenido que uno de sus acreedores, Japonica Partners L.P., había adquirido votos para impedir la aprobación del plan de reorganización propuesto por el deudor, y así asegurarse de la aprobación de su propio plan, que le concedía propiedad sobre el deudor insolvente. En este caso el tribunal resolvió que "Japonica actuó con motivos ulteriores para adquirir y controlar al deudor, en lugar de actuar meramente para proteger sus intereses económicos como acreedor" (Sección I.B) (traducción del autor). Disponible en: https://coursewebs.law.columbia.edu/coursewebs/ cw 12S L8247 001.nsf/0f66a77852c3921f852571c100169cb9/80E18046115D71E0852579 9D00816ADC/\$FILE/In re Allegheny Intl, Inc, 11 [1].pdf?OpenElement [fecha de visita 7 de enero de 2013]. 
Finalmente, comprobada la mala fe por parte del solicitante, corresponderá al tribunal el descarte del voto impugnado, como si este nunca hubiese sido emitido. Como agrega Africk, las facultades de la corte se encuentran limitadas, de tal suerte que solo cabe una descalificación del voto in toto, esto es, respecto a todos los créditos del acreedor de mala $\mathrm{fe}^{24}$. De ahí que la sección 1.126(e) USC 11, más que descarte del voto, se refiere al descarte del votante. Asimismo, agregamos, el tribunal no puede tener por rechazado el acuerdo alcanzado por el resto de los acreedores, ni podrá promover una nueva votación del plan, sino que simplemente dejará de contar los votos correspondientes al votante excluido.

En tal sentido, en In re DBSD North America, Inc., la Corte de Apelaciones del Segundo Distrito, consideró suficientemente acreditados todos los extremos para descartar el voto de DISH. A su juicio, este habría obrado de mala fe, en términos tales que "deseaba conseguir una posición de bloqueo y controlar el proceso concursal para obtener un activo potencialmente estratégico" 25 . A reglón seguido, tuvo por aprobado el plan con el voto conforme de los demás acreedores ${ }^{26}$.

\section{3) CoMentarios}

Como anticipáramos, nuestro interés en abordar este caso jurisprudencial se centra en la comprensión de una regla que sustenta el derecho a voto en la propia justificación del Derecho concursal. El Derecho norteamericano ha incluido la citada sección 1.126(e) en su Código de Bancarrotas a efectos de atajar las motivaciones de quienes desatienden la finalidad de maximización del retorno por parte de los acreedores, que es precisamente el parámetro de conducta que se pretende de quien actúa como tal en el contexto concursal. La concesión del derecho a voto, hemos señalado, advierte una función tutelar del derecho de crédito, y en este sentido no puede ser estimado en términos absolutos, sino desde la perspectiva funcional que permite conseguir tal objetivo.

Este elemento tiene sentido en los modelos en los que se aprecia que la principal finalidad del concurso se encuentra en la protección de los intereses de los acreedores, al tiempo que entiende que deben ser estos los primeros llamados en materializar tal tutela, expresando su voluntad, especialmente por medio del ejercicio del derecho a voto ${ }^{27}$. Esta idea se ha manifestado bajo la idea de la "privatización" del Derecho concursal, tér-

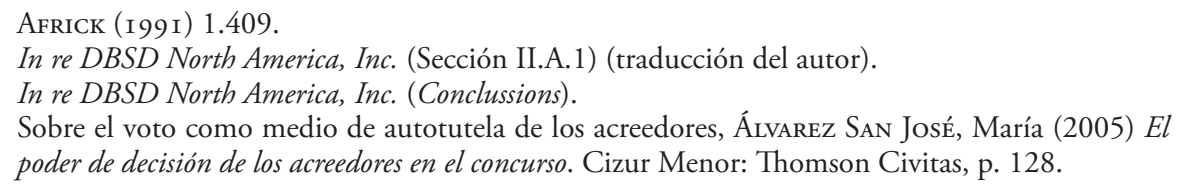


mino que, aunque algo impreciso, es explicado por Di MARzio como la retirada de la regla que ofrece una solución típica al problema de la insolvencia, para dar espacio a la expresión privada en ámbitos anteriormente proscritos por la propia norma ${ }^{28}$.

Esta visión supone, paralelamente, la pérdida del poder de los órganos públicos (en general, como ejecutores de la regla legalmente impuesta) y la concesión de un engrosado haz de facultades de dirección, administración y disposición a los particulares ${ }^{29}$. Con ello se enfatiza la finalidad distributiva del concurso, construido este como un mecanismo de coordinación entre los acreedores, a fin de alcanzar un resultado conducente a una mayor eficiencia que la que propone la ejecución singular ${ }^{30}$. Esta argumentación ha sido el principal postulado de quienes han abordado el análisis del Derecho concursal desde una perspectiva económica, especialmente a partir de los trabajos de JACKsOn sobre la materia ${ }^{31}$. El citado autor ha promovido incansablemente una interpretación de las instituciones concursales como aquellas destinadas a dotar de una cierta organicidad a fin de que los acreedores resuelvan el conflicto suscitado a raíz de la insolvencia, observando el patrimonio del deudor como un recurso común que, sin reglas de coordinación, está destinado a la tragedia ${ }^{32}$.

Entonces, el parámetro de eficiencia económica resultará en una herramienta de política legislativa ${ }^{33}$, o en un "criterio normativo que inspira la totalidad de la legislación de quiebras"34. Aquel se manifestará en la articulación de una finalidad primaria de la solución concursal,

28 Di Marzio, Fabrizio (2011) Il Diritto Negoziale della Crisi D Impesa. Milán: Giuffrè Editore, p. 4.

29 Macario, Franceso (2010). "Insolvenza del debitore, crisi dell'impresa e autonomia negoziale nel sistema della tutela del credito". En Di Marzio, Fabrizio y Macario, Franceso (directores): Autonomia Negoziale e Crisi D'Impresa. Milán: Giuffrè Editore, p. 22. Así también, Álvarez (2005) 127, relacionando el punto con la construcción de un modelo privatista por parte del ordenamiento jurídico, señala que "Una concepción restrictiva, que limite a los acreedores stricto sensu el círculo de los afectados por la insolvencia, postula un modelo de intervención público-judicial mínima, que simplemente proporcione un marco que permita la ordenada toma de decisión por los acreedores sobre la solución del procedimiento".

30 Para una explicación de este punto, Goldenberg Serrano, Juan Luis (2010). "Consideraciones críticas respecto al denominado principio de la par condicio creditorum”. Revista Chilena de Derecho, Vol. 37, N 1, pp. 73-98, p. 83.

31 Jackson, Thomas H. (1986). The Logic and Limits of Bankruptcy Law. Cambridge: Harvard University Press. Así también, Jackson, Thomas H. y Scott, Robert E. (1989). "On the nature of bankruptcy: An essay on bankruptcy sharing and the creditors' bargain”. Virginia Law Review, Vol. 75, $\mathrm{N}^{\circ}$ 2, Symposium on the Law and Economics of Bargaining, pp. 155-204.

32 JACKSON (1986) 11.

33 Tirado Martí, Ignacio (2009). "Reflexiones sobre el concepto de "interés concursal” (Ideas para la construcción de una teoría sobre la finalidad del concurso de acreedores)". Anuario de Derecho Civil, Tomo LXII, fascículo 3, pp. 1.055-1.108, p. 1.079.

34 Núñez Ojeda, Raúl; Carrasco, Nicolás y Ortiz Rojo, Francisco (2012). "Visión crítica desde el análisis económico del derecho al sistema de verificación de créditos y realización de activos en la ley de quiebras chilena”. Ius et Praxis, Año 18, Nº 1, pp. 267-314, p. 271. 
como es la tutela del crédito $^{35}$, la cual se reflejará, ya en concreto, en la conformación de su principal objetivo: la "maximización del beneficio de los acreedores, que se traduce en una mayor tasa de recuperación de sus créditos" 36 .

Entendido de este modo, y reconduciendo esta aproximación a las reglas que conceden el derecho a voto, es que es comprensible tanto la limitación impuesta por la sección 1.126(e) USC 11, como la interpretación que la jurisprudencia norteamericana ha dado a la expresión "buena fe" contenida en ella. De ahí la correcta conclusión de In re DBSD North America, Inc., como también de los precedentes jurisprudenciales anotados, que hacen sinónimos la "mala fe" con la existencia de "motivos ulteriores", configurando estos como aquellos presentes en todos los casos en los que la decisión de voto no se ha orientado conforme al objetivo primordial del concurso antes apuntado, como es la maximización de las posibilidades de cobro del crédito.

Ahora bien, nos ha interesado efectuar los alcances anteriores particularmente para hacer un contrapunto con la regulación concursal chilena, vigente y proyectada. Ello porque, como hemos anticipado, nuestro sistema se estructura también desde una perspectiva eminentemente privatista del Derecho concursal ${ }^{37}$.

Sin perjuicio de lo anterior, el modelo propiciado por nuestra legislación concursal vigente no parece dar pie a la elaboración de un parámetro general de pérdida de derecho a voto por la sola demostración de que este puede ser o ha sido emitido sin la intención de dirigirse a una solución que resulte eficiente a la luz de la finalidad tutelar del concurso. Al contrario, veremos, esta posibilidad se circunscribe a un listado taxativo de casos que, tomando únicamente en cuenta un elemento subjetivo (de

35 Comparativamente, en el Derecho español, Olivencia, Manuel (2010). "La satisfacción de los acreedores, fin esencial del concurso". En Rojo, Ángel y Beltrán, Emilio (directores): Los Acreedores Concursales, II Congreso Español de Derecho de la Insolvencia. Cizur Menor: Civitas Thomson Reuters, pp. 31-47, acoge esta visión, aunque ello no se proponga expresamente del articulado de la legislación concursal, sino que se proclame solo en su exposición de motivos (II, párrafo cuarto). En otras legislaciones, ello aparece de algún modo de manifiesto: por ejemplo, el artículo 1 de la Insolvenzordnung alemana dispone que "los procedimientos concursales deben servir el propósito de la satisfacción colectiva de los créditos del deudor por medio de la liquidación de sus activos y por la distribución de sus resultados, o por medio del acuerdo de un plan de insolvencia, particularmente en orden a conservar la empresa" (traducción del autor); y, con una precisión que parece propia de un texto de análisis económico del derecho, el artículo I de la Ley General del Sistema Concursal peruana, dispone que "el objetivo del sistema concursal es la permanencia de la unidad productiva, la protección del crédito y el patrimonio de la empresa. Los agentes del mercado procurarán una asignación eficiente de sus recursos durante los procedimientos concursales orientando sus esfuerzos a conseguir el máximo valor del patrimonio en crisis".

36 NúñEZ/Carrasco/Ortiz (2012) 273.

37 Núñez Ojeda, Raúl y Carrasco Delgado, Nicolás (2011). Derecho Concursal Procesal Chileno. Santiago de Chile: Abeledo Perrot Thomson Reuters, p. 231. 
cercanía al deudor) o de alteración de las mayorías necesarias para tomar acuerdos (por medio de fraccionamientos o cesiones de créditos), intuye la posibilidad que, tras el mismo, se oculte una intención que desatienda el interés común de los acreedores.

En primer término, y paralelamente al sistema anglosajón, consideramos que el derecho a voto, como pilar fundamental de la configuración de los derechos de los acreedores en concurso, debe entenderse limitado solo de manera excepcional, $y$, en tal caso, dichas limitaciones deben interpretarse de manera restringida. En este sentido, llama la atención que la Corte de Apelaciones de Santiago, conociendo de la impugnación de un convenio en razón de la inteligencia fraudulenta entre acreedores y el deudor (artículo 196 N³ del Libro IV del Código de Comercio), haya resuelto negativamente tal pretensión considerando, entre otros, la actitud del abogado del acreedor demandante, quien en la correspondiente Junta Extraordinaria de Acreedores solicitó "que, conforme al artículo 179, se deje votar a todos los acreedores", y "no hubiese pedido de inmediato su exclusión de la Junta de Acreedores" 38 . Ello puesto que la inteligencia fraudulenta podrá justificar la impugnación del convenio, conforme reza la norma citada, pero en caso alguno priva directa y preventivamente del derecho a voto a los acreedores.

En segundo lugar, nuestra legislación sorprende por la distancia tomada en sus reacciones normativas en supuestos de quiebra y convenio, pues estas no son equivalentes. De hecho, la sospecha de la obstrucción a los fines de eficiencia en el voto solo parecería tener relevancia en este último caso, como si no se previera que el poder direccional de los acreedores en quiebra pudiese, en los hechos, dar cuenta de iguales interferencias exógenas. Considérese especialmente que, en el caso de quiebra, corresponderá a los acreedores la decisión de la forma en que se realizarán los bienes del fallido (artículo 120 del Libro IV del Código de Comercio), incluyendo la posibilidad de su venta como unidad económica (artículos 123 y siguientes), e, incluso, la aprobación de la continuidad efectiva de giro como mecanismo conducente a la satisfacción del pasivo (artículos 112 y siguientes). Se trata de un punto a resolver por parte del legislador, especialmente en la medida en que se ha verificado un constante aumento del poder decisorio de los acreedores, incluso en un escenario naturalmente liquidatorio.

De hecho, en supuesto de quiebra, la privación de derecho a voto solo se referirá al caso en que se haya producido un fraccionamiento de créditos después de declarada la quiebra, confiriendo mandato por una

38 Corte de Apelaciones de Santiago. 16 de enero de 2007. Rol No. 4.228. "Sociedad Inmobiliaria y de Inversiones San Cristóbal con Inmobiliaria Toscana" (considerandos décimo segundo y décimo tercero). Disponible en la base de datos LegalPublishing, bajo el código CL/ JUR/3779/2007. 
parte o fracción de créditos. Si bien el artículo 104 del Libro IV del Código de Comercio solo sanciona al contraventor y los que representen porciones de créditos con la pérdida del derecho a asistir a la junta, la consecuente privación del derecho a voto es evidente en tanto solo en junta aquel podrá ser emitido. La razón, en este caso, no estará dada por las interferencias en el ejercicio del derecho a voto, sino solo en evitar maniobras por parte de los acreedores que pretendan aumentar artificialmente el número de acreedores (no así el monto del pasivo) necesario para la conformación de mayorías ${ }^{39}$.

En un sentido diametralmente opuesto, el artículo 190 del Libro IV del Código de Comercio, ya en sede de convenios judiciales, priva de derecho a voto (como asimismo del cómputo de sus créditos para el cálculo del pasivo) a: "a) El cónyuge, los ascendientes y descendientes y hermanos del deudor o de sus representantes, sin perjuicio de lo dispuesto en el articulo 193; b) Las personas que se encuentren en alguna de las situaciones a que se refiere el artículo 100 de la ley $N^{\circ}$ 18.045, de Mercado de Valores, y c) El titular de la empresa individual de responsabilidad limitada proponente del convenio, y esta empresa individual si el proponente es su titular" 40.

La cercanía del acreedor, familiar o patrimonial, supondrá que el legislador deteriore su posición en el concurso, en tanto supondrá que este de alguna manera representará, incluso encubiertamente, las pretensiones del deudor, y no la que tutele los intereses generales de los acreedores. Este sistema automático de privación del voto revela que el legislador no está interesado en la comprobación de las sospechas en que fundamenta su decisión, esto es, no desea judicializar el derecho a voto, bastándole la

39 En similar sentido, nuestra jurisprudencia ha intentado proteger el régimen de mayorías legalmente previsto evitando que los acreedores manipulen el quórum requerido para la aprobación de un convenio judicial. De este modo, nuestra Corte Suprema ha fallado que "Los mecanismos utilizados por el legislador contemplan exclusivamente la abstención para los acreedores preferentes, de manera tal que los valistas con derecho a voto, cualquiera sea su posición frente a la proposición del convenio, no pueden ser excluidos del total del pasivo, puesto que su voluntad fue contemplada por el legislador encaminada a la aceptación o rechazo de la propuesta, mas no a la variación de un hecho objetivo, como es el pasivo de la quiebra, que no admite subjetivización” [Corte Suprema. 16 de marzo de 2011. Rol No. 5.775-2010. “Tesorería General (Fisco) c. Corporación de Fútbol Profesional de la Universidad de Chile” (considerando décimo). Disponible en la base de datos LegalPublishing, bajo el código CL/JUR/2150/2011].

40 Obsérvese que, excepcionalmente, el artículo 193 del Libro IV del Código de Comercio agrega que las personas indicadas en la letra a) del artículo 190 tendrán derecho a voto en cuanto se opongan al convenio, caso en el cual sus créditos se incluirán en el pasivo. Ello porque, de prosperar la oposición (artículo 209), se deberá declarar la quiebra del deudor (tratándose de un convenio judicial preventivo) o mantener la misma (si se trata de un convenio alzatorio), lo que evidenciaría la divergencia de intereses entre este último y su cónyuge y parientes cercanos. En cualquier caso, un estudio crítico sobre estas reglas puede encontrarse en PUga VIAL, Juan Esteban (2006). Derecho concursal. El Convenio de Acreedores. Santiago de Chile: Editorial Jurídica de Chile, pp. 276-282. 
acreditación de la circunstancia de hecho -representada por la tipología contemplada en el citado artículo 190- que motiva su pérdida.

Algo similar ocurre con la privación del derecho a voto a los cesionarios de créditos adquiridos dentro de los 30 días anteriores a la proposición del convenio, que, conforme al artículo 191 del Libro IV del Código de Comercio, no podrán concurrir a la junta para deliberar y votar el convenio, como tampoco podrán impugnarlo ni actuar en el incidente de impugnación. La lógica de esta regla, nos señala PUGA, se fundamenta esencialmente en que "se produzcan negociaciones entre acreedores o entre personas asociadas al deudor o sus empresas, destinadas a reunir en manos seguras créditos que significan la mayoría. Lo mismo se da por el lado de los acreedores, que para impedir la formación de convenios, adquieren créditos de otros acreedores" ${ }^{41}$.

Pero estas razones parecen no compadecerse ni con la justificación de la pérdida de derecho a voto en el Derecho comparado ${ }^{42}$, especialmente en el Derecho norteamericano al que hemos hecho referencia, ni con la conformación de un creciente mercado de pasivos concursales, al que apuntaba Rouillon, citado al inicio de este comentario. Lo primero porque la tutela no parece suficiente en la medida que no comprenda créditos cedidos en el periodo que media entre las proposiciones de convenio y su votación, momento en que la posibilidad de adquisición de créditos parece propicia para la obtención de la mayoría deseada ${ }^{43}$; lo segundo, porque la sospecha de intereses contradictorio con las finalidades de eficiencia debería someterse a un filtro más exigente que el mero cambio de acreedores, de manera de justificar una reacción tan extrema por parte del ordenamiento, como es la privación del derecho a voto.

41 Puga (2006) 246.

42 En el Derecho español, por ejemplo, las cesiones de créditos con posterioridad a la apertura del concurso dará lugar a la pérdida del derecho a voto (artículo 122.1 de la Ley Concursal). Al respecto, Quijano González, Jesús (2004). "Artículo 122 - Acreedores sin derecho a voto”. En Pulgar Ezquerra, Juana; Alonso Ureba, Alberto; Alonso Ledesma, Carmen y Alcover Garau, Guillermo (directores): Comentarios a la Legislación Concursal. Madrid: Dykinson, p. 1.163, sostiene que "la ley proyecta una especial "desconfianza" sobre las adquisiciones de créditos una vez declarado el concurso, porque resulta extrańo que alguien desee adquirir voluntariamente un crédito sobre el que hay serias dudas respecto a su cobro íntegro y puntual, una vez que el deudor ha confesado su insolvencia o esta le ha sido constatada. Parece como si a esta adquisición se le supusieran algún tipo de móviles extraños o intenciones torcidas y, otra vez como reacción preventiva, se privará de voto a tales créditos para evitar que puedan interferir, influir, condicionar, etc., las decisiones sobre las propuestas de convenio".

43 Asimismo, Contreras STrauch, Osvaldo (2010). Insolvencia y Quiebra. Santiago de Chile: Editorial Jurídica de Chile, p. 364, objeta esta norma por cuanto "si se permite que en el proceso de deliberación y votación del convenio un acreedor pueda excluir a otro pagándole (art. 190), lo que importa en el fondo una especie de adquisición del respectivo crédito, no se advierte la razón por la cual deba impedirse la participación y votación en la junta de los cesionarios de créditos cedidos con anterioridad a la presentación del convenio y menos aún si se tiene en cuenta que, como hemos dicho, eliminado el texto del antiguo art. 173, en la actualidad las proposiciones de convenio pueden ser discutidas antes de la junta”. 
En nuestro ordenamiento vigente, la taxatividad de las excepciones antes anotadas hará que interferencias exógenas de otro orden solo permitan la impugnación, no del voto, que aparece como un derecho absoluto, sino del resultado de la votación en la medida que haya llevado a la aprobación del convenio. Ello únicamente en el caso en que haya mediado "inteligencia fraudulenta entre uno o más acreedores y el deudor para votar a favor del convenio o para abstenerse de concurrir" (artículo 196, $\mathrm{N}^{\circ}$ 3 del Libro IV del Código de Comercio). Pero este supuesto es ostensiblemente limitado, por cuanto no observa únicamente las motivaciones internas ("ulteriores") del acreedor al tiempo de votar, sino que exige adicionalmente de la existencia de fraude y de concierto con el deudor para la obtención de un provecho en perjuicio de los demás acreedores ${ }^{44}$. Los casos que, paralelamente, anota la jurisprudencia norteamericana a la que hemos hecho referencia, y donde puede encontrarse también un peligro para la lógica del sistema, no requieren de dichos elementos, especialmente en lo que se refiere al concierto con el deudor.

Nos parece altamente conveniente que una revisión del sistema chileno, esencialmente privatista, aproveche la experiencia comparada sobre este punto, como propone el artículo 191, inciso segundo, del proyecto de reforma concursal, aunque limitadamente en el contexto de las liquidaciones concursales, obligando a la abstención en el ejercicio del derecho a voto en lugar de la privación legal del mismo, y, más confuso aún, haciendo girar la norma sobre la sola existencia de un interés extracrediticio, aunque este no sea considerado por el acreedor al tiempo de su votación.

Esta cuestión es particularmente relevante dada la creciente profundidad de nuestro mercado, anticipándose a la posibilidad de que entidades decidan adquirir créditos concursales a fin de torcer la finalidad de eficiencia pretendida por el legislador. Sin embargo, comprendemos que el punto debe ser abordado con cierta cautela, especialmente ante la eventualidad de que una fórmula de solución muy amplia (como la propuesta por el derecho norteamericano, bajo el estándar genérico de la buena fe) puede dar lugar a la judicialización del proceso concursal, en una época en que la experiencia comparada aboga por la "desjudicialización" del mismo ${ }^{45}$; al tiempo que una redacción muy estrecha (como la que consagra el ordenamiento español, privando del voto en caso de haberse perfeccionado cualquier clase de cesión del crédito) puede terminar desterrando

Puga (2006) 320 y 321.

Al respecto, Rocco di Torrepadula, Nicola (2008): "La governance nel fallimento". En Sarcina, Antonio y García Cruces, José Antonio (directores): Il Trattamento Giuridico della Crisi d'Impresa. Profili di Dirito Concorsuale Italiano e Spagnolo a Confronto. Bari: Cacucci Editore, pp. 9-16, p. 10. 
la existencia de un mercado de créditos concursales, que incluso puede resultar útil para el mejor resultado del concurso ${ }^{46}$.

\section{4) Bibliografía}

- Africk, Andrew (1991). "Trading claims in Chapter 11: How much influence can be purchased in good faith under section 1126". University of Pennsylvania Law Review, Vol. 139, No 5, pp. 1.3931.422 .

- Álvarez San José, María (2005) El poder de decisión de los acreedores en el concurso. Cizur Menor: Thomson Civitas.

- Broude, Richard (1984). "Cramdown and Chapter 11 of the Bankruptcy Code: the settlement imperative". The Business Lawyer, No39, pp. 441-454.

- Contreras Strauch, Osvaldo (2010) Insolvencia y Quiebra. Santiago de Chile: Editorial Jurídica de Chile.

- Di Marzio, Fabrizio (2011). Il Diritto Negoziale della Crisi D'Impesa. Milán: Giuffrè Editore.

- Goffman, Jay M. y Lovetr, Suzanne D.Y. (2010). "Confirmation Hot Topics". En Bankruptcy 2010: Views from the Bench. Nueva York: American Bankruptcy Institute, pp. 145-167.

- Goldenberg Serrano, Juan Luis (2010). "Consideraciones críticas respecto al denominado principio de la par condicio creditorum". Revista Chilena de Derecho, Vol. 37, No 1, pp. 73-98.

- Jackson, Thomas H. (1986). The Logic and Limits of Bankruptcy Law. Cambridge: Harvard University Press.

- Jackson, Thomas H. y Sсотt, Robert E. (1989). "On the nature of bankruptcy: An essay on bankruptcy sharing and the creditorsbargain". Virginia Law Review, Vol. 75, N ${ }^{\circ} 2$, Symposium on the Law and Economics of Bargaining, pp. 155-204.

- Kidder, Samuel M. (2010-2011). "What's your position? Amending the Bankruptcy disclosure rules to keep pace with financial innovation”. UCLA Law Review, N 803, pp. 803-841.

- Macario, Franceso (2010). "Insolvenza del debitore, crisi dell'impresa e autonomia negoziale nel sistema della tutela del credito”. En Di Marzio, Fabrizio y Macario, Francesco (directores): Autonomia Negoziale e Crisi D'Impresa. Milán: Giuffrè Editore.

- Núñez Ojeda, Raúl y Carrasco Delgado, Nicolás (2011). Derecho Concursal Procesal Chileno. Santiago de Chile: Abeledo Perrot Thomson Reuters. 
- Núñez Ojeda, Raúl, Carrasco Delgado, Nicolás y Ortiz Rojo, Francisco (2012). "Visión crítica desde el análisis económico del derecho al sistema de verificación de créditos y realización de activos en la ley de quiebras chilena”. Ius et Praxis, Año 18, N 1, pp. 267 314.

- Olivencia, Manuel (2010). "La satisfacción de los acreedores, fin esencial del Concurso”. En Rojo, Ángel y Beltrán, Emilio (directores): Los Acreedores Concursales, II Congreso Español de Derecho de la Insolvencia. Cizur Menor: Civitas Thomson Reuters, pp. 31-47.

- Puga Vial, Juan Esteban (2006). Derecho concursal. El Convenio de Acreedores. Santiago de Chile: Editorial Jurídica de Chile.

- Quijano GonzÁlez, Jesús (2004). "Artículo 122 - Acreedores sin derecho a voto". En Pulgar Ezquerra, Juana; Alonso Ureba, Alberto; Alonso Ledesma, Carmen y Alcover Garau, Guillermo (directores): Comentarios a la Legislación Concursal. Madrid: Dykinson, pp. 1.159-1.166.

- Roulllon, Adolfo (2007). "El cambio del paisaje concursal a comienzos del siglo XXI". Anuario de Derecho Concursal, N 11, pp. 253-261.

- Tirado Martí, Ignacio (2009). "Reflexiones sobre el concepto de "interés concursal" (Ideas para la construcción de una teoría sobre la finalidad del concurso de acreedores)". Anuario de Derecho Civil, Tomo LXII, fascículo 3, pp. 1.055-1.108.

- Warren, Elizabeth (2008). Chapter 11: Reorganizing American Business. Nueva York: Wolters Kluwer, Aspen Publishers. 